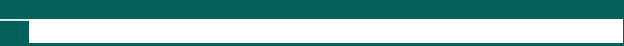

SECCIÓN: Problemas espaciales contemporáneos
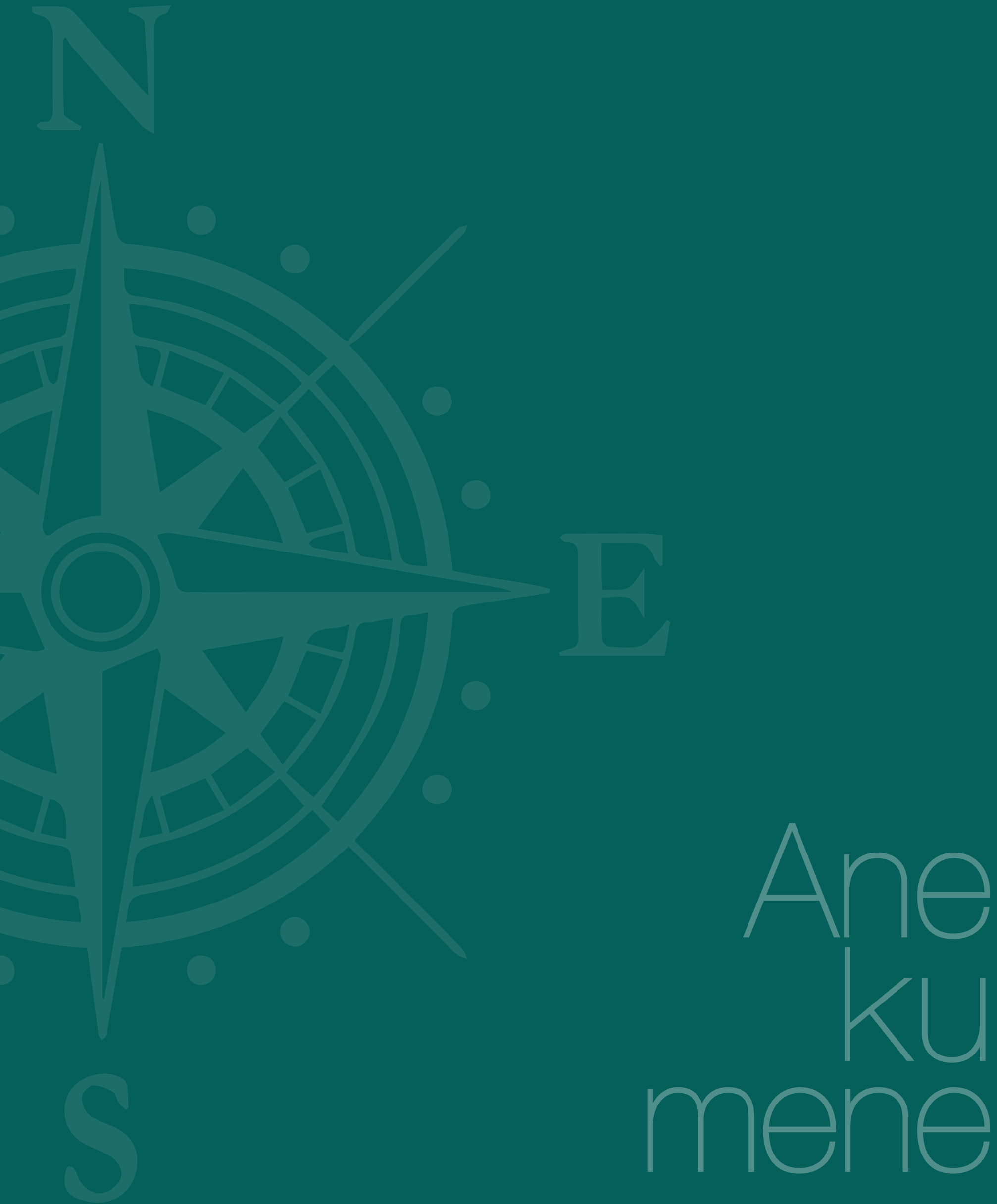


\section{A Didática e a Geomorfologia: uma experiência interdisciplinar na formação de professores de Geografia}

Didactics and Geomorphology: An Interdisciplinary Experience in the Training of Geography Teachers

La didáctica y la geomorfología: una experiencia interdisciplinar en la formación de profesores de geografía

Waldiney Gomes de Aguiar*

Julio Cesar Paisani**

\section{Resumo}

A busca pela qualidade do ensino passa necessariamente pelo crivo da ciência e dos conteúdos empíricos desenvolvidos nas aulas de formação de professores: ao mesmo tempo em que é preciso valorizar os conteúdos científicos a fim de superar o senso comum, é também necessário considerar o conhecimento prévio dos alunos, a ser superado em sua formação acadêmica. Este artigo trata de uma aula interdisciplinar de Didática e Geomorfologia, a qual proporcionou aos acadêmicos a possibilidade de compreender que, em sua atuação como professores de Geografia da educação básica, não devem lidar com conteúdos fragmentados, mas articulados, buscando ensinar conteúdos curriculares e, também, refletir sobre como ensiná-los, criando estratégias para tal.

\section{Palavras-chave}

ensino de Geografia; prática de ensino; conteúdo curricular; Educação Básica; relevo

* Profesor Universidade Estadual do Norte do Paraná - Campus Cornélio Procópio

** Profesor do Curso de Bacharelado em Geografia, Universidade Estadual do Oeste do Paraná 
A Didática e a Geomorfologia: uma experiência interdisciplinar

na formação de professores de Geografia

Waldiney Gomes de Aguiar / Julio Cesar Paisani /

\section{Abstract}

The search for the quality of teaching necessarily goes through the scrutiny of science and the empirical contents developed in teacher training classes: While it is necessary to value scientific content in order to overcome common sense, it is also necessary to consider the prior knowledge of students to be surpassed with their academic training. This article deals with an interdisciplinary class on didactics and geomorphology, which provided academicians with the possibility of understanding that, in their work as geography teachers of basic education, they should not deal with fragmented but articulated contents, seeking to teach curricular contents, as well as to reflect on how to teach those contents, creating strategies for that purpose.

\section{Resumen}

La búsqueda de la calidad de la enseñanza pasa necesariamente por el escrutinio de la ciencia y de los contenidos empíricos desarrollados en las clases de formación del profesorado: a la vez que es necesario valorizar los contenidos científicos para superar el sentido común, también es necesario considerar el conocimiento previo de los alumnos que se va a superar en su formación académica. El presente artículo hace referencia a una clase interdisciplinaria de Didáctica y Geomorfología que le proporcionó a los académicos la posibilidad de comprender que, en su actuación como profesores de geografía de la educación básica, no deben lidiar con contenidos fragmentados, sino articulados, buscando enseñar contenidos curriculares y también reflexionar sobre cómo enseñarlos, creando estrategias para lo mismo.

\section{Keywords}

Geography teaching; teaching practice; curricular content; basic education; relief

\section{Palabras clave}

enseñanza de geografía; práctica de enseñanza; contenido curricular; educación básica; relieve 


\section{Introdução}

A construção do conhecimento requer a compreensão da parte do professor de que aquilo que é ensinado em suas aulas deve ter significado para os alunos. Para que isso ocorra, é preciso ter em mente a importância tanto dos conhecimentos curriculares predeterminados pelas escolas como das maneiras de socializá-los. A fim de garantir um ensino que leve os alunos a entender, por exemplo, os fenômenos geográficos naturais, sociais ou econômicos, é também necessário que o docente "domine" tais conhecimentos do ponto de vista científico, caso contrário corre-se o risco de ensinar apenas os conteúdos provenientes do senso comum ou simplesmente repassar o que está escrito nos livros. Se for esta a prática do professor, a escola estará apenas informando os alunos sobre algo que já conhecem empiricamente, ou retransmitindo em cópia servil o que apresentam os livros, sem nenhuma mediação que possibilite a construção do conhecimento.

Para que uma aula possa ter sentido para os alunos, e eles construam conhecimentos a partir do que já sabem, é preciso mostrar-lhes para que servem os conteúdos curriculares em seu dia a dia. Para tanto, além de "dominar" os conhecimentos curriculares científicos a serem ensinados, o professor deve organizar suas aulas a partir de situações que levem os alunos a pensar sobre o que estão estudando. Nesse sentido, a Didática serve tanto para desvendar os conhecimentos científicos como para organizar uma aula. Ela deve ser entendida como um processo de ensino, e não como uma ferramenta que ajuda o professor a transmitir conhecimentos considerados prontos.

Desse modo, a organização de uma aula, no contexto que estamos propondo, deve partir de uma situação, ou seja, o professor deve definir os conteúdos curriculares científicos a serem ensinados e, em seguida, elaborar um problema a ser resolvido pelos alunos que lhes permita criar hipóteses e socializá-las com os demais colegas em sala de aula, apresentando resposta(s) ao problema elaborado pelo professor. Nesse processo, o docente é muito mais um mediador, isto é, ele instiga os alunos a pensarem sobre o que lhes foi colocado como desafio.

Assim, nota-se que, atravessando a situação didática, três tipos de conteúdos curriculares devem estar articulados, os conceituais, os procedimentais e os atitudinais, que assim se configuram: o primeiro remete aos conceitos dos conteúdos curriculares a serem estudados; o segundo consiste em que os alunos saibam identificar os conceitos adquiridos, por exemplo, em uma paisagem ou em um mapa; o terceiro implica poder agir ou reagir diante de situações referentes ao que se aprendeu. Todo esse processo de ensino mediado pelo professor ajuda os alunos a construir seus próprios conhecimentos, nos três âmbitos de conteúdo aqui mencionados.
Dessa forma, a aula de Geografia passa a ser mais significativa tanto para o professor como para os alunos. De um lado, o docente faz a articulação entre o conhecimento geográfico e a Didática, a fim de proporcionar um ensino que considera os saberes empíricos da cultura dos alunos com o objetivo de mostrar-lhes sua relação com os conteúdos científicos; de outro, os discentes têm a oportunidade de participar das aulas como construtores de seus próprios conhecimentos, que serão utilizados em variadas situações de seu cotidiano e convívio social, principalmente no que respeita ao lugar onde moram.

Nesse sentido, as aulas interdisciplinares articulando Didática e Geomorfologia, propostas pelo presente estudo, desenvolveram-se da seguinte maneira: na primeira aula de Didática, foi apresentada aos alunos a imagem de um fenômeno natural popularmente conhecido por "deslizamento de encosta", a fim de que eles socializassem suas respectivas hipóteses sobre o assunto, apontando possíveis causas de tal ocorrência. Nessa mesma aula, foram também abordados os conceitos de conteúdos conceituais, procedimentais e atitudinais, para que os alunos entendessem a importância de cada um deles na construção do conhecimento, visando a sua utilidade no dia a dia das pessoas. Em seguida, na aula de Geomorfologia, o professor reapresentou a mesma imagem utilizada na aula de Didática, para que os alunos novamente socializassem suas hipóteses, iniciando a partir delas o ensino dos conteúdos conceituais acerca do "deslizamento de encosta" apresentado. Levantadas às hipóteses e apropriando-se dos conhecimentos científicos, os alunos teriam de reelaborar seus conhecimentos sobre o assunto, transformando-os em conhecimentos científicos em forma de texto a ser disponibilizado em murais na sala de aula.

\section{A Didática como processo de ensino dos conteúdos científicos na formação do professor de Geografia}

Ensinar Geografia tem sido um desafio para os professores, principalmente no âmbito da educação básica. Afirmamos isso nos colocando na situação de pesquisadores e docentes de formação de professores de Geografia, que buscam não apenas entender esse fenômeno, mas também contribuir de alguma forma para ao menos minimizar o problema. Nesse sentido, temos acompanhado tais demandas pedagógicas nos diferentes níveis de ensino, no que concerne ao aprender e ao ensinar os conteúdos geográficos, e percebemos que algo deve ser feito na tentativa de superar esses obstáculos pedagógicos.

Diante disso, partimos do princípio de que o professor de Geografia deve articular suas aulas por meio de um processo didático capaz de correlacionar conteúdos curriculares conceituais, procedimentais e atitudinais, visando a uma aprendizagem significativa para o aprendiz. Desse modo, a Didática, como disciplina curricular presente no curso de formação de 
professores de Geografia, não deve ser apenas uma matéria que ensina os acadêmicos a "passar" os conteúdos geográficos. No que se refere à formação docente, ela deve proporcionar aos alunos o entendimento da ciência geográfica como conhecimento indispensável para a sociedade, a compreensão de sua importância na construção do espaço geográfico, considerando-se suas categorias - tais como território, lugar, paisagem e região -, além de, de maneira geral, levar os alunos a compreender seu objeto de estudo.

Desse modo, a Didática na formação de professores de Geografia apresenta-se como ciência para ensinar outra ciência. É por isso que ela, em nosso entendimento, na condição de disciplina curricular de um curso de formação de professores de Geografia, deve ser compreendida como um processo de ensino, deixando assim de ser, como é costumeiramente chamada, a arte de transmitir conhecimentos, para tornar-se um processo de construção de conhecimentos.

Assim, de acordo com Brousseau (2008, p. 117), "um professor espera que a didática lhe proporcione ao menos o conteúdo essencial das técnicas específicas das noções ensinadas, técnicas compatíveis com suas concepções gerais de pedagogia e educação". De maneira geral, conforme percebemos em nossos estudos, a preocupação dos docentes consiste, em maior escala, em como dar aulas a seus alunos utilizando inovações baseadas em materiais didáticos, sem se preocupar em articular tais recursos didáticos a algum fundamento teórico que justifique sua utilização.

Conforme se vê, utilizando um material didático em sala de aula, compreendendo que o ensino no sentido amplo da palavra abrange concepções pedagógicas e educacionais, o professor provavelmente desenvolverá sua aula estando consciente de que a formação dos educandos passa pelo crivo do fato de eles serem construtores de conhecimentos, e não meros espectadores em sala de aula, recebendo informações sem a possibilidade de questionar. Pelo contrário, eles devem participar da aula como sujeitos do processo didático.

Nesse sentido, conforme assevera Raths (1977, p.4), "Se os professores proporcionarem uma vida escolar rica em oportunidade para pensar, é muito provável que a maioria dos alunos modifique seu comportamento." Muitas vezes, o docente apresenta aos alunos o que eles devem fazer nas aulas, a fim de mudar o comportamento diante do que se estuda, normalmente fazendo com que "sigam" o que lhes foi posto como caminho para alcançar as respostas desejadas pelo professor a partir de seu planejamento. Esse procedimento é um dos elementos que compõem o processo didático.

Além das regras colocadas pelo professor em uma aula, é preciso também dar aos alunos a oportunidade de pensar sobre o que estão estudando, uma vez que suas perguntas acerca do que é proposto pelo professor podem ser importantes para haver construção de conhecimento mútuo, ou seja, para que, de um lado, o aluno apresente suas dúvidas e erros e, de outro, o professor reformule seu plano de aula, a fim de atender as necessidades específicas dos discentes- tudo com um só objetivo: o ensino e a aprendizagem.

Apenas dizer aos alunos que eles precisam pensar para resolver uma questão sobre a aula pode não ser suficiente, sendo necessário propiciar condições para que efetivamente reflitam. Para isso, a forma de organizar a aula também deve ser pensada, implicando o estabelecimento de tipos de recursos didáticos a serem utilizados de acordo com o conteúdo,como o uso de uma imagem para trabalhar um determinado conteúdo de Geomorfologia. Nesse caso, o professor elabora um problema, socializa-o com os alunos a fim de que estes expressem suas apreensões acerca do que está representado na imagem e, a partir daí, desencadeia suas explicações científicas sobre os conteúdos geomorfológicos, visando superar os conceitos de senso comum mencionados pelos alunos.

A cada aula, outros recursos didáticos podem ser acrescentados, como uma maquete para representar em três dimensões a imagem explorada. Isso possibilita ao acadêmico entender que os conteúdos conceituais são importantes, e podem ganhar ainda mais relevância se estiverem articulados à maneira de ensiná-los, relacionando-se conteúdo, procedimentos didáticos e o tempo para aprender aos poucos, sem a preocupação de "vencer" a lista de conteúdos curriculares.

A relação entre conteúdos, procedimentos e o tempo da aula pode ser um obstáculo na prática de ensino. De um lado, observa-se o professor tentando avançar rapidamente suas aulas a fim de cumprir a lista de conteúdos curriculares predeterminados e, de outro, o aluno com suas demandas de aprendizagem, tais como o tempo para aprender e a forma de aprender intrínseca a sua própria natureza como ser único, indivíduo que possui potencialidades e dificuldades próprias na aprendizagem.

De acordo com Pozo e Crespo (2009, p.22), "não é mais possível conceber a aprendizagem como uma atividade apenas de reprodução ou cumulativa". Assim, percebe-se que o procedimento aos moldes cumulativos, ou seja, aquele tradicionalmente chamado de conteudístico, não privilegia as características cognitivas, específicas de cada indivíduo, que condicionam a forma de aprender, aspecto que nem sempre é levado em consideração.

Considerar nas aulas o que os alunos sabem acerca de determinados assuntos não é nenhum demérito à aula planejada pelo professor. Antes, é ter um ponto de partida para ensinar os conteúdos científicos e mostrar que os conhecimentos produzidos pelos cientistas estão no contexto da cultura de um povo ou da preocupação com um determinado fenômeno. Assim os alunos podem compreender as relações existentes entre o que sabem e o conteúdo curricular, dando lugar ao ensino como um processo de educação científica. A esse respeito, pode-se afirmar que 
A eficácia da educação científica deverá ser medida pelo que conseguimos que os alunos realmente aprendam. E para isso é necessário que as metas, os conteúdos e os métodos de ensino da ciência levem em consideração não apenas o saber disciplinar que deve ser ensinado, mas também as características dos alunos a quem esse ensino vai dirigido e as demandas sociais e educacionais que o ensino deve satisfazer. (Pozo \& Crespo, 2009, p. 27)

Na formação de professores, de maneira ampla, um dos grandes dilemas tem sido o debate entre os que acreditam que basta os acadêmicos apropriarem-se dos conhecimentos científicos do currículo para desenvolver uma boa aula, e aqueles que postulam ser também necessário que o futuro professor aprenda a socializar os conteúdos, para haver aprendizagem. Chegar a uma conclusão e apresentar respostas para esse problema não seria tarefa fácil, porém alguns "caminhos" terão de ser trilhados nesse campo do saber, haja vista nossa proposta de trabalhar uma atividade com nossos alunos nas disciplinas de Didática e Geomorfologia.

Portanto, partimos do princípio de que todos os conhecimentos são "frutos" de uma cultura uma vez que são produzidos a partir das demandas sociais que se perpetuam ou se perdem na história, embora sejam passíveis de resgate. Os conhecimentos dos quais os indivíduos se apropriam em seu grupo cultural, seja pelas experiências dos mais "velhos", seja por observações ou convívio com seus pares, são o que configura sua história no tempo e no espaço, o que corresponderia ao saber espontâneo ou empírico. O saber espontâneo não garante necessariamente a evolução cultural de uma sociedade por simples acúmulo de conhecimento, sendo necessário compreender que novos saberes são construídos no decorrer do tempo histórico e que eles precisam ser explicados. Sendo assim, a ciência encarrega-se de explicar os fenômenos de forma sistematizada, normalmente nas escolas.

É a partir da escola que os conhecimentos científicos produzidos são socializados, sendo também nessa mesma instituição que os saberes das diversas culturas das quais fazem parte os alunos se apresentam como saberes. Isso não acarreta nenhum problema, se tais saberes forem tratados como conhecimentos que se relacionam em sua essência. De acordo com Bachelard (1972,),"Existe ruptura entre o conhecimento sensível e o conhecimento científico. Lemos a temperatura num termômetro; não a sentimos. Sem a teoria nunca saberíamos se aquilo que vemos e aquilo que sentimos correspondem ao mesmo fenômeno."(p.17).

Assim, um tema muito discutido entre professores da educação básica tem sido a relação entre a teoria e a prática em sala de aula. De um lado, os professores buscam, em suas práticas em sala de aula, enfatizar a importância de ensinar os conteúdos curriculares a partir da prática; de outro, na academia parece ocorrer o contrário, isto é, dá-se ênfase aos aspectos teóricos, segundo o ponto de vista do docente, da base escolar.
Parece-nos ser esse um dilema a ser resolvido. Conforme o autor supracitado, nas atividades escolares, tanto a teoria como a prática devem ser colocadas em situação de igualdade, não se justificando nenhuma prática nas aulas de Geografia - seja a construção de uma maquete com o intuito de explicar aos alunos o perfil do relevo nas três dimensões, seja localizar em um mapa as várias coordenadas geográficas -, sem sua articulação a uma base teórica científica. Caso ocorra a prática pela prática simplesmente, o conteúdo curricular estaria sendo ensinado sem o cunho científico, submetendo os alunos a uma tarefa sem a preocupação de mostrar-lhes que o que fazem estaria relacionado com a ciência geográfica. Por exemplo, ao construir uma maquete, o professor poderia, além de mostrar aos alunos o perfil de um relevo em três dimensões, aprofundar a temática e a oportunidade da situação para estudar a gênese do relevo. Na sequência, por meio de um mapa, poder-se-ia localizar a ocorrência de fenômenos relacionados ao relevo, levantando-se hipóteses e construindo novos conhecimentos. Para haver um ensino pautado na construção do conhecimento, no qual alunos e professores participem como indivíduos integrantes de um processo de ensino, é preciso, de acordo com nossa abordagem crítico-teórica, que tanto a teoria como a prática estejam articuladas em sala de aula, para que não se perca a cientificidade, no ensinar e também no aprender.

De acordo com Castellar e Moraes (2012, p.121), “o professor deve apropriar-se de seus conhecimentos teórico-metodológicos e de sua experiência para atuar qualificativamente na escola". Isso implica dizer que a formação do profissional professor passa essencialmente pelo crivo do domínio dos conteúdos curriculares na academia e por sua experiência de vida em seu percurso histórico, somando-se ainda a Didática, a fim de que ele possa desenvolver sua atividade com competência na sala de aula. Ele deve considerar ainda todo o contexto em que estão inseridos seus alunos, com o objetivo de ensinar os conteúdos curriculares a partir do viés científico e cultural. Essa nos parece ser uma atribuição desse profissional que, de maneira geral, não está consolidada na prática escolar. Tal fato nos indica que existe um "caminho" vasto a ser percorrido na formação inicial e continuada, com o intuito de superar a dicotomia teoria-prática já amplamente questionada no ensino e aprendizagem, como se uma fosse alheia à outra, sem haver nenhum vínculo pedagógico. Ao contrário, entendemos que o ensino sem base científica corresponderia apenas ao conhecimento empírico.

Segundo Moraes (2010), ao se trabalhar o conhecimento científico em sala de aula, deve-se ter em mente a necessidade de que ele ocorra a partir da vivência dos alunos, a partir da qual eles levantam hipóteses sobre os fenômenos estudados, buscando compreender o mundo do ponto de vista científico, a fim de ajudá-los a elaborar sua argumentação. Isso implica dizer que o ensino dos conteúdos geográficos precisa articular procedimentos didáticos, conteúdos curriculares e a ciência geográfica. Isso exige que o professor esteja preparado para organizar sua aula considerando o ensino como um processo e garantindo a seus 
alunos a possibilidade de compreender o lugar em que vivem e sua relação com outros lugares, estabelecendo-se um contraponto entre o que sabem sobre os fenômenos naturais, sociais ou econômicos, tendo a ciência como base para tal compreensão.

Nesse sentido, tanto a Didática como a Geomorfologia, disciplinas ministradas aos acadêmicos do segundo ano do curso de Geografia da instituição a que estamos vinculados, são indispensáveis para sua formação profissional, haja vista a importância de os alunos concluírem o curso de graduação estando capacitados para desenvolver uma aula na educação básica provida tanto de conteúdos conceituais como procedimentais. Isso significa que estarão preparados para compreender os fenômenos estudados em sala de aula, bem como identificar os conteúdos atitudinais relacionados, que lhes servirão para agir ou reagir diante de ocorrências ligadas aos conhecimentos adquiridos. É com essa reflexão que nos propusemos a desenvolver uma situação didática que levasse aos alunos a possibilidade de pensar sobre a importância dos conteúdos curriculares a partir da articulação entre o conhecimento sensível, ou seja, o que trazem consigo no seu percurso histórico de vivência e o conhecimento científico.

\section{Contribuição da disciplina Geomorfologia para desvendar fenômenos naturais: o caso dos "deslizamentos de encostas"}

A disciplina Geomorfologia trabalha especificamente com a explicação da gênese e evolução das formas de relevo em diferentes escalas temporais e espaciais. A amplitude e especialidade de seu foco a credenciam como um campo científico autônomo que busca explicar as paisagens de nosso planeta. Durante muitas décadas a formação e dinâmica das paisagens naturais têm sido interpretadas a partir da gênese e evolução das formas de relevo. Diante disso, o principal componente de uma paisagem seria as formas de relevo. As formas de relevo podem ser um componente principal na distinção das paisagens, mas não se resumem somente a isso.

\section{Desenvolvimento da situação didática}

a. Apresentação do problema aos alunos pelo professor, neste caso, por meio de uma imagem.

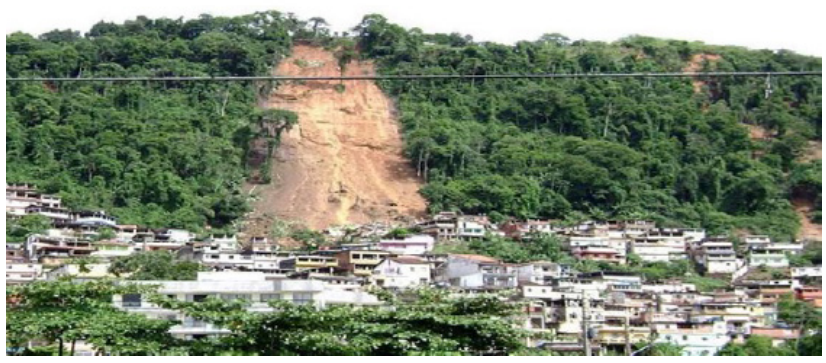

Fonte: Danielle Viana/Foto Repórter/AE - Folha de São Paulo

b. Na situação, o professor da disciplina de Didática solicitou aos acadêmicos que elaborassem suas hipóteses acercado problema apresentado a partir da imagem. Os alunos foram instigados, em grupos pequenos, a criar estratégias para resolver o problema colocado, sendo importante, nesse momento, registrar suas hipóteses no caderno, para em seguida socializá-las com os colegas. Assim, eles criaram suas hipóteses sobre as causas e consequências do fenômeno observado na imagem.

c. Em seguida, durante algumas aulas, o professor da disciplina de Geomorfologia explicou aos alunos os conceitos científicos relacionados à imagem apresentada. Para explicar os conteúdos conceituais, partiu-se das hipóteses levantadas pelos alunos, considerando-se a imagem e o enunciado-problema.

d. Depois, foram explicados os conteúdos científicos relacionados à situação-problema apresentada aos alunos e, tendo-lhes mostrado como identificar os fenômenos estudados, a partir de suas respectivas hipóteses, articuladas aos conhecimentos científicos adquirindo-o que implica o trabalho com os conteúdos procedimentais -, o professor mostrou como reconhecer os fenômenos estudados na perspectiva do conhecimento sensível, de suas hipóteses, e na perspectiva do conhecimento científico. Lembrando que esses conteúdos são os que os alunos deverão reconhecer, seja em uma paisagem, seja, por exemplo, uma imagem ou um mapa.

e. Nesse momento, o professor mostrou aos alunos como agir ou reagir diante do fenômeno estudado. Esse procedimento constitui os denominados conteúdos atitudinais, devendo o professor mostrar ao aluno as atitudes necessárias, desenvolvidas de acordo com o conteúdo estudado na aula, frente à ocorrência de um fenômeno na realidade. Por exemplo, o aluno deve reconhecer que tirar a vegetação de uma encosta para construir casas pode acarretar desastres relacionados a deslizamentos.

f. Ao final da atividade, os alunos apresentaram suas hipóteses iniciais, estabeleceram uma relação com os conteúdos científicos 
estudados, criaram novas hipóteses, defenderam-nas em forma de debate em sala de aula e, em seguida, organizaram uma forma de divulgar os conhecimentos construídos. Assim, foram confeccionados cartazes a serem afixados no mural da sala de aula, considerando que a exposição das atividades proporciona a possibilidade de o aluno reler o que foi feito, em outros momentos, e criar novas hipóteses, construindo outros conhecimentos.

\section{Resultados observados}

Na sequência, serão apresentados os resultados obtidos a partir da aplicação da situação didática descrita, fornecendo alguns excertos das hipóteses e conceituações tecidas pelos alunos, bem como a nossa análise a respeito.

\section{Algumas hipóteses iniciais dos alunos nas aulas de Didática}

- "O deslizamento é resultante de alto índice de chuva"

- "A desigualdade social faz com que pessoas acabem construindo suas casas em locais de risco"

- "As ocupações irregulares podem causar transtorno aos moradores"

- "O desmatamento causa desmoronamento de encostas".

As hipóteses dos alunos acerca da imagem apresentada na aula de Didática sobre um "deslizamento de encosta" aparecem de maneira espontânea e aparentemente convenceriam, caso se considerasse apenas o senso comum. No entanto, se não houver mediação do professor com o objetivo de permitir aos alunos avançar conceitualmente para, a partir do que já sabem sobre o assunto, irem em busca da explicação científica dos conteúdos, há o risco de chegar-se ao denominado obstáculo pedagógico, ou seja, o aluno não superar o conhecimento já adquirido, não o relacionando aos conhecimentos científicos. Para evitar esse impasse, ao propor que elaborem suas hipóteses sobre determinados temas da Geografia, o professor deve possibilitar um debate na aula, na qual surgem opiniões diferentes e, assim, novos conhecimentos vão sendo construídos, mesmo que inicialmente de forma empírica, para posteriormente estabelecer-se a relação com os conceitos científicos. Tal processo constituiria a superação de um obstáculo pedagógico.

\section{Apropriação dos conteúdos científicos nas aulas de Geomorfologia}

Durante as aulas de Geomorfologia, explicou-se que existem diferentes fenômenos relacionados à erosão do solo. Geralmente, reconhecem-se fenômenos associados à erosão canalizada e não canalizada. Os fenômenos relacionados à erosão canalizada decorrem dos caminhos que a água naturalmente percorre em uma encosta. Alterações de ordem natural ou antrópica nos fatores que controlam esses fenômenos podem desencadear a erosão canalizada. Já no que concerne à erosão não canalizada, trabalharam-se os movimentos coletivos de solo ou rocha, os quais são popularmente entendidos como "deslizamentos de encosta", mas conceitualmente constituem as situações específicas deum único fenômeno, designado "movimento de massa". No caso das encostas tropicais e subtropicais, geralmente há um espesso manto de intemperismo generalizadamente chamado de "solo". A partir daí, trataram-se as categorias de movimentos de massa associados à erosão do solo, recorrendo-se a uma classificação aceita na maior parte dos manuais das Geociências, que discerne os movimentos de massa segundo sua velocidade, conteúdo de água e sedimentos. Foi assim que os alunos puderam perceber que a imagem trabalhada apresentava um movimento de massa de alta velocidade, cujo material desprendido foi completamente envolvido em água, caracterizando um fluxo denso de terra.

Essa nova concepção para o fato apresentado na imagem foi materializada pelos alunos na elaboração dos cartazes, na tentativa de explicar o fenômeno. Algumas passagens registraram os conhecimentos adquiridos:

- "A água da chuva é o principal fator de erosão"

- "São diversas as variáveis que determinam se uma encosta é estável ou instável: o ângulo de repouso, a natureza do material na encosta, a quantidade de água infiltrada nos materiais, a inclinação da encosta e a presença de vegetação".

- "Esses fatores são condicionantes"

- "[...] o fenômeno trata-se de um fluxo denso, uma das categorias de movimentos de massa [popularmente chamado de deslizamento de encosta], onde a quantidade de água em relação à quantidade de material pode ter sido $50 \%$, fazendo com que o material rompesse e se movimentasse como um fluido viscoso"

- " "[...] fluxos densos ou fluxos gravitacionais viscosos são aqueles em que a viscosidade deve-se à significativa concentração de sedimentos"

A partir dos conhecimentos prévios dos alunos em relação ao deslizamento de encosta, agora entendido como "movimento de massa" e, na situação específica, como fluxo denso de terra, entrou em cena o professor de Geomorfologia para ajudar os estudantes a entenderem cientificamente os conteúdos antes conhecidos apenas empiricamente. Nessa fase da atividade, o professor traz para sua aula as hipóteses dos alunos, construídas previamente na aula de Didática, e mostra-lhes, para cada uma delas, seus respectivos conceitos científicos, levando os alunos a pensar sobre o que sabiam anteriormente e, consequentemente, superar os obstáculos pedagógicos. Tais obstáculos são importantes para o processo de aprendizagem uma vez que constituem parte indispensável 
da construção de conhecimento, não devendo ser considerados pelo docente como um erro, descartando-se o que os alunos sabem e vivenciam no dia a dia, mas como um ponto de partida para tornar a aula um momento de discussão científica, visto que só assim o senso comum se transforma em algo que possibilita aos alunos fazer descobertas.

\section{Exemplos de conhecimentos construídos a partir dos conteúdos elencados}

1. Conteúdos conceituais: "Movimento de massa, a água das chuvasé o principal fator causador de erosão e intemperismo nas encostas, voçoroca, fluxos gravitacionais viscosos e ravinas".

2. Conteúdos procedimentais: "Pode ocorrer um possível movimento de massa através do aparecimento de ravinas e voçorocas".

3. Conteúdos atitudinais: "Para evitar catástrofes, não se devem construir casas em áreas de risco de desmoronamento, próximo a encostas".

Considerações dos alunos: "É de grande importância o conhecimento espontâneo, ou seja, as hipóteses apresentadas a partir de uma problemática, para se constituir o conhecimento conceitual, procedimental e atitudinal. Nesse sentido, percebe-se a ligação entre a primeira ideia, o senso comum, nesse caso o 'desmoronamento em encosta' (movimento de massa), e o conhecimento científico, o qual é conceituado como fluxos densos. Esse fenômeno também pode ser denominado de fluxo de lama ou de detritos.

"Para evitar que ocorra o deslizamento de encosta, conforme a problemática apresentada a partir da imagem, uma solução seria repor a vegetação para que a água desça pelas encostas das montanhas perdendo velocidade e infiltre no solo em maior quantidade".

\section{Considerações}

Em primeiro lugar, é importante dizer que a reflexão acerca de uma aula interdisciplinar em um curso de formação de professores de Geografia, tal como é o caso de nosso escopo, requer acima de qualquer posição filosófica e metodológica o apreço de quem a propõe, voltado para um único objetivo, a saber, a qualidade do ensino e a certeza de que tanto a forma de ensinar como os conteúdos curriculares científicos são imprescindíveis para a futura atuação dos acadêmicos em sala de aula.

Nesse sentido, o problema apresentado aos acadêmicos na aula de Didática foi o início de uma discussão que acreditávamos culminar em respostas as mais variadas possíveis, fato ocorrido. Mesmo que oriundas do senso comum, as respostas apresentadas nos levam a crer que, de certa forma, os alunos conhecem os fenômenos naturais, que neste caso consistem em um "deslizamento de encosta" (conceitualmente designado de movimento de massa), conhecimento que provém seja da mídia ou mesmo da observação empírica, olhando-se diretamente para um determinado relevo. 0 desmatamento das encostas, segundo os alunos, é a principal causa da ocorrência do movimento de massa nas encostas, além da utilização desses locais para fins imobiliários, fatores que podem aumentar os riscos à segurança da sociedade.

Nossa proposta inicial de trabalhar um conteúdo curricular do curso de formação de professores de Geografia de maneira interdisciplinar parecia difícil, já que essa abordagem, de maneira geral, não é comum na academia, pois seus cursos não costumam estabelecer projetos em comum, restringindo-se à própria formação de cada professor que ali atua. Felizmente, o convite ao professor de Geomorfologia gerou frutos. Isso suscita reflexões cerca de algumas resistências que carregamos desde nossa formação inicial, segundo as quais a responsabilidade da formação de professores deve ser imputada aos professores das disciplinas consideradas "pedagógicas", termo cuja conceituação deixamos em suspenso, tanto por considerá-lo abrangente, como pelo fato de julgarmos que a formação está amplamente vinculada a todas as disciplinas. Essas resistências também passam pelo crivo da interpretação do que é um curso de formação de professores e quais seus objetivos. Em primeiro lugar, independentemente da formação de cada professor formador na academia, é preciso ficar claro que as disciplinas, por cujo ensino os professores são responsáveis, possuem o mesmo valor, devendo-se considerar o ensino como um processo e não mera transmissão de informações fragmentadas e isoladas, como se cada uma delas desse, por si mesma, aos acadêmicos a capacidade e a habilidade para ministrar suas futuras aulas aos alunos da educação básica.

O grau de importância das disciplinas para a formação dos acadêmicos deve ser o mesmo, afinal estamos, nos cursos de formação de professores, ensinando ciência, de forma ampla. Com esse trabalho, perceberam-se as implicações desse debate, que permeia a Geografia, através da valorização em separado da Geografia Física e da Geografia Humana, restando ainda, entre elas, a questão do ensino - como se os três elementos estivessem isolados ou devessem ser ensinados apenas em suas particularidades científicas, não se considerando, por exemplo, ao estudar um "deslizamento de encosta" (movimento de massa), que os riscos não seriam apenas naturais. Nesse sentido, é importante ressaltar que o aluno precisa ter domínio dos conteúdos científicos do currículo e que essa apropriação dá-se por meio das disciplinas consideradas "específicas". Além disso, que a Didática também tem sua importância no âmbito das ciências, devendo ser encarada não apenas como uma disciplina que visa a ensinar os alunos a elaborar planos de aula. Pelo contrário, ela vai muito além, no sentido de uma apropriação dos conhecimentos didáticos científicos, a fim de poder entender que os conteúdos ministrados em uma aula de Geografia apresentam toda uma complexidade em sua construção, desde as primeiras pesquisas, a interpretação do pesquisador, a transposição para os livros até se chegar à sala de aula. 
É nesse contexto que a Didática colabora como ciência que pode ajudar o professor a entender as outras ciências, seus conteúdos curriculares e, consequentemente, a ensiná-los a partir do conhecimento empírico, com o objetivo maior de não perder a cientificidade.

Para iniciar um debate acerca das aulas, tal como aqui propomos e encetamos, retomamos os objetivos principais da aula. Lançar uma pergunta aos alunos a partir de uma foto de um deslizamento de encosta foi o desafio inicial, já que muitas respostas ou a maioria delas foram empíricas, devendo ser transformadas em científicas. A pergunta serve para estimular os alunos a participar das aulas, mesmo que com respostas do senso comum, consistindo em um ponto de partida para a construção de novos conhecimentos, ou seja, o conhecimento científico. Assim se alcança como vimos o chamado obstáculo pedagógico, que deve ser superado pelos alunos com a ajuda do professor.

Ao organizar uma aula interdisciplinar, o professor deve pensá-la como um processo de ensino, considerando sua prática de socialização e o conteúdo a ser ministrado. Dada essa compreensão, os conteúdos devem ser entendidos como conteúdo conceitual, procedimental e atitudinal. Tal como vimos, o primeiro diz respeito aos conceitos dos conteúdos curriculares, isto é, os conteúdos científicos propriamente ditos; o segundo consiste em como reconhecer, por exemplo, o fenômeno estudado na aula a partir da imagem apresentada, ou seja, no caso, consiste em saber como identificar a possibilidade de deslizamento; e o terceiro seria o que fazer diante de um fenômeno identificado como passível de causar riscos à própria pessoa ou à sociedade de maneira geral.
Os resultados obtidos a partir das respostas dos alunos mostraram que é possível organizar uma aula interdisciplinar no curso de formação de professores, sem nenhum desmerecimento às disciplinas, além de mostrar a importância de cada uma delas como ciência que poderá contribuir com a sociedade de maneira geral. Acreditamos que as aulas estabelecidas a partir de uma resolução de problemas - e considerando os conteúdos mencionados anteriormente - só têm a contribuir, visto ter sido mostrado que os alunos aprendem e se sentem participantes ativos do processo de ensino, e não meros espectadores que recebem informações prontas, sem a possibilidade de questionar, reelaborar e construir novos conhecimentos.

Além disso, no que tange aos docentes do curso de formação de professores, como é o nosso caso, percebemos que muito há a fazer no campo da interdisciplinaridade, ou seja, na aproximação das disciplinas, a fim de trabalhar em conjunto visando à melhoria na qualidade do ensino de Geografia. Assim, ao somarmos essa experiência a outras e, aos poucos, também ao construirmos novos conhecimentos a partir de uma revisão em nossa prática, a partir do entendimento de que a ciência possibilita que reflitamos sobre ela, questionamos tanto nossa prática em sala de aula como também o valor científico dos conteúdos para a formação dos professores de Geografia.

\section{Referências}

Bachelard, G. (1972). Filosofia do novo espírito científico. Lisboa: Presença.

Brousseuau, G.(2008) Introdução ao estudo da teoria das situações didáticas: conteúdos e método de ensino. (C. Bógea, Trad.). São Paulo: Ática,.

Castellar, S., \& Moraes, J.(2012). Um currículo integrado e uma prática escolar interdisciplinar: possibilidades para uma aprendizagem significativa. Em:. S. Castellar, \& G. Munhoz (Orgs.).Conhecimentos escolares e caminhos metodológicos. São Paulo: Xamã.

Pozo, J., \& Crespo, M.(2009). A aprendizagem e o ensino de Ciências: do conhecimento cotidiano ao conhecimento científico. (N Freitas, Trad.). Porto Alegre: Artmed.

Raths, L. E. (1977). Ensinar a pensar.(D. Leite, Trad.). 2 ed. São Paulo: EPU. 